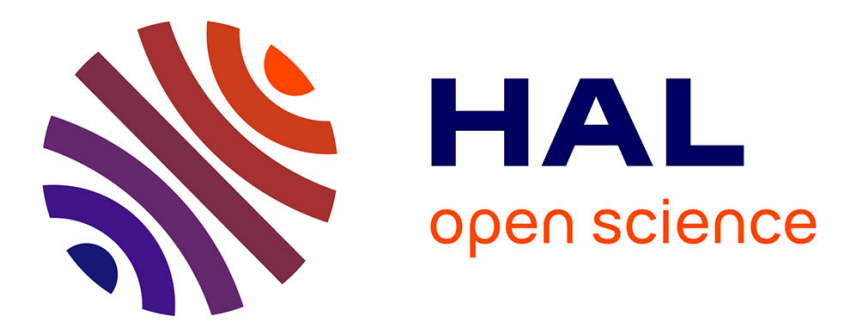

\title{
Contrast microbubble clustering at high MI
}

Michiel Postema, Michal Mleczko, Georg Schmitz

\section{To cite this version:}

Michiel Postema, Michal Mleczko, Georg Schmitz. Contrast microbubble clustering at high MI. 2006 IEEE Ultrasonics Symposium, Oct 2006, Vancouver, Canada. pp.1564-1567, 10.1109/ULTSYM.2006.397 . hal-03193337

\section{HAL Id: hal-03193337 \\ https://hal.science/hal-03193337}

Submitted on 11 Apr 2021

HAL is a multi-disciplinary open access archive for the deposit and dissemination of scientific research documents, whether they are published or not. The documents may come from teaching and research institutions in France or abroad, or from public or private research centers.
L'archive ouverte pluridisciplinaire HAL, est destinée au dépôt et à la diffusion de documents scientifiques de niveau recherche, publiés ou non, émanant des établissements d'enseignement et de recherche français ou étrangers, des laboratoires publics ou privés. 


\title{
Contrast microbubble clustering at high MI
}

\author{
Michiel Postema, Michał Mleczko, Georg Schmitz
}

Institute for Medical Engineering, Ruhr-Universität Bochum, Bochum, Germany

\begin{abstract}
The driving of contrast microbubbles towards a boundary by means of primary radiation (Bjerknes) forces has been of interest for ultrasound-assisted drug delivery. Secondary radiation forces, resulting from oscillating microbubbles under ultrasound insonification, may cause the mutual attraction and subsequent coalescence of contrast microbubbles. This phenomenon has been less studied. Microbubbles with a negligible shell can be forced to translate towards each other at relatively low mechanical indices (MI). Thick-shelled microbubbles would require a higher MI to be moved. However, at high MI, microbubble disruption is expected. We investigated if thick-shelled contrast agent microbubbles can be forced to cluster at high-MI. Two thick-shelled contrast agents, inserted through a cellulose capillary, were subjected to $3 \mathrm{MHz}$, highMI pulsed ultrasound from a commercial ultrasound machine, and synchronously captured through a high numerical aperture microscope. The agent Quantison ${ }^{\mathrm{TM}}$ did not translate, but showed a small percentage of disrupted bubbles. The agent M1639 showed the ultrasound-induced formation of bubble clusters, and the translation thereof towards the capillary boundary. It is concluded, that forced translation and clustering of thick-shelled contrast microbubbles is feasible.
\end{abstract}

\section{INTRODUCTION}

Ultrasonic imaging is a relatively cheap, reliable diagnostic technique. In clinical ultrasound, blood cells cannot be differentiated from surrounding tissue, due to the low acoustic impedance difference between blood cells and their surroundings. A contrast agent has been added to the blood that helps to differentiate between blood and other tissue types, which consist of low-solubility gas microbubbles encapsulated by a stabilizing shell, small enough to pass through the lung capillaries. The resonance frequencies of ultrasound contrast agent microbubbles lie within the clinical diagnostic range. Agents can be designed to specifically target a receptor system [1], thus facilitating ultrasonic molecular imaging [2]. Ultrasonic contrast-enhanced imaging applications depend on the detectability of microbubbles. The detectability in turn depends on the ultrasonic pulsing scheme, which in turn depends on the predictability of the contrast microbubble behavior. To improve the predictability of the dynamic behavior of contrast agents, we have been observing contrast microbubbles under insonification.

Translations of ultrasound contrast agent microbubbles in the direction of the sound field and towards each other have been frequently observed with high-speed cameras [3], [4], [5]. Here, we investigate bulk bubble behavior using camera footage during ultrasound insonification. We are especially interested in bubble-bubble interaction. Microbubbles with a negligible shell, and therefore a high compressibility,

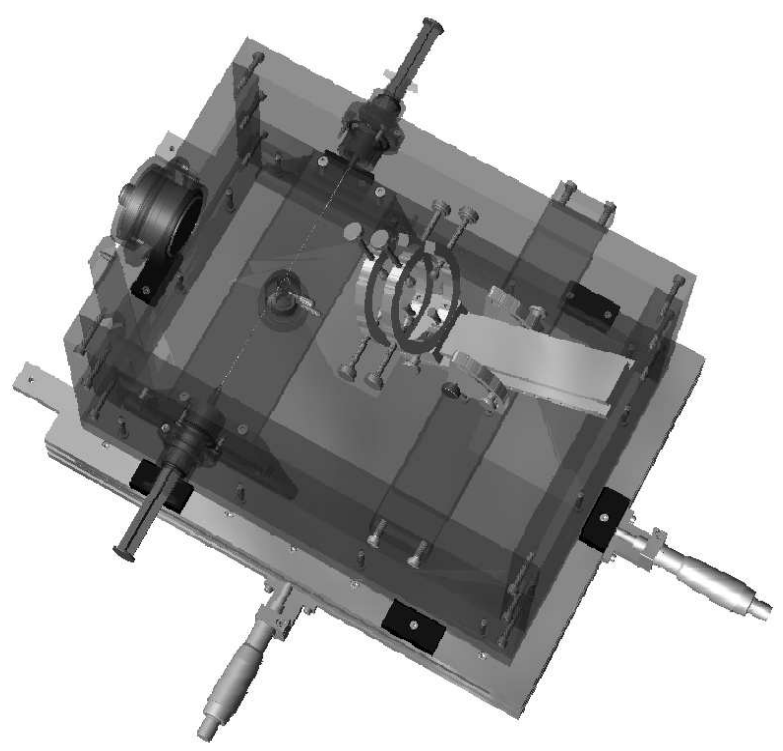

Fig. 1. Top view of experimental setup container on top of $x-y$ table. The capillary, attached to the syringes, is spanning the full width.

can be forced to translate towards each other at relatively low mechanical indices (MI) [5]. Because of their lower compressibility, thick-shelled microbubbles would require a higher MI to be moved. However, at high MI, microbubble disruption is expected. We investigated if thick-shelled contrast agent microbubbles can be forced to cluster at high-MI.

\section{THEORY}

Microbubble translation in the direction of the sound field has been attributed to a primary radiation (Bjerknes) force resulting from a pressure gradient across the bubble surface. The translation is maximal in contraction phase [6]. The microbubble translations towards each other have been attributed to secondary radiation forces: oscillating bubbles generate spatially varying pressure fields. If two bubbles are either both below or both above the resonant size, this results in attraction. However, if one bubble is below and the other is above the resonant size, they oscillate out of phase [6], [7], causing the bubbles to recede from each other. The mean approach velocity $v_{\mathrm{a}}$ of two identical bubbles is given by [3]:

$$
v_{\mathrm{a}}=-\frac{\left(\omega p^{-}\right)^{2}}{27 \eta} \rho \kappa^{2} \frac{r_{0}^{5}}{d_{0}^{2}}
$$



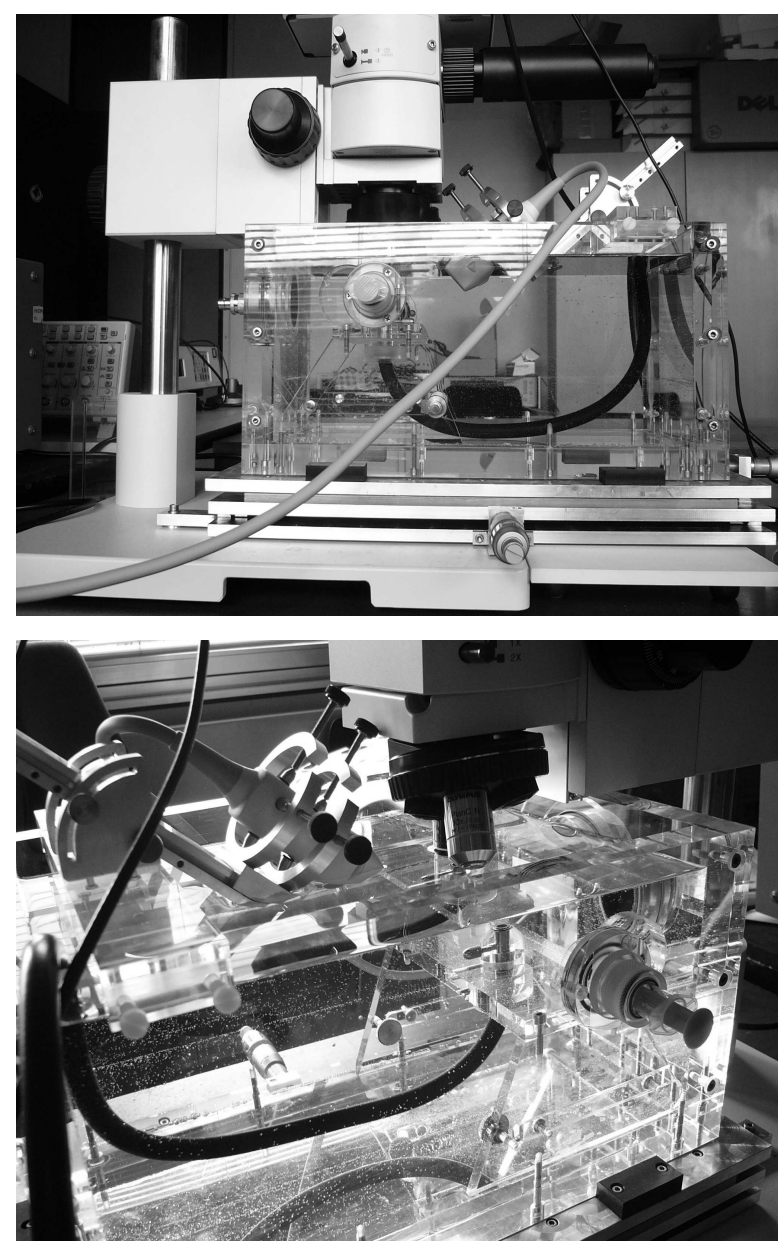

Fig. 2. Photographs of the experimental setup during operation.

where $d_{0}$ is the distance between the centers of the two bubbles, $p^{-}$is the peak rarefactional acoustic pressure, $r_{0}$ is the bubbles' equilibrium radius, $\eta$ is the shear viscosity of the fluid, $\rho$ is the density of the surrounding fluid, $\omega$ is the angular insonifying frequency, and $\kappa$ is the compressibility of the bubble

$$
\kappa=\frac{1}{\rho} \frac{\partial \rho}{\partial p},
$$

in which $\frac{\partial \rho}{\partial p}$ is the partial derivative of the density with respect to the pressure.

\section{EXPERIMENTAL SETUP}

The experimental setup has been designed for simultaneous optical and acoustical observations of ultrasound contrast agents. The measurements are done in a Perspex container filled with deionized water, which stands on top of a custom-built micron-adjustable $x-y$-table ( $c f$. Figure 1). A single-element transducer can be mounted to the side of the container. Also, there is a holder for conventional array transducers of commercial echo machines. To circumvent attenuation effects of the microbubbles between the transducer surfaces and the acoustic foci, the contrast agent is inserted through a syringe into a CUPROPHAN ${ }^{\circledR}$ RC55 cellulose capillary (Membrana GmbH, Wuppertal, Germany) with a $200 \mu \mathrm{m}$ inner diameter and an $8 \mu \mathrm{m}$ wall thickness. This capillary spans the full width of the container. The central part of the capillary has been illuminated from below by a DC21 40,000 footcandle fiber optic continuous light source (StockerYale, Inc., Salem, NH, USA). On top of the capillary, focused at the capillary, there is a LUMPlanFL $60 \times$ high numerical aperture $(\mathrm{NA}=0.90)$ water immersion objective lens (Olympus Deutschland GmbH, Hamburg, Germany) with a $2 \mathrm{~mm}$ working distance. The microscopic system is a customized BXFM-F unit (Olympus), with two eyepieces and two separate camera outlets. The spherical foci of our single-element transducers and of the array transducer coincide with the optical focus, allowing for simultaneous optical and acoustical interrogation ( $c f$. Figure 2).

For calibration of the optical system, we used a microelectronic device with a $6.1 \mu \mathrm{m}$ wire width (cf. Figure 3), recorded with a WAT-902DM monochrome CCD camera (Watec Co., Ltd., Tsuruoka-Shi, Yamagata-Ken, Japan).

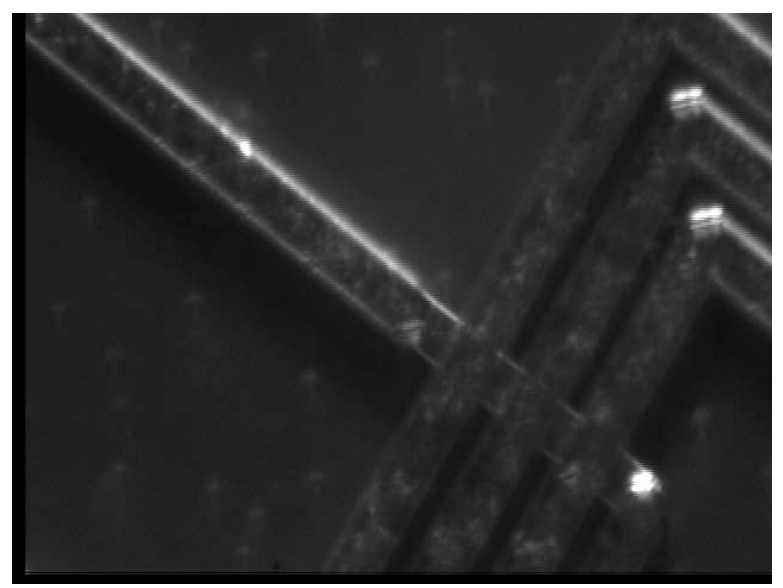

Fig. 3. Photograph through microscopic system of microelectronic device with $6.1 \mu \mathrm{m}$ wire width. The frame corresponds to a $94.4 \times$ $70.8 \mu \mathrm{m}^{2}$ area.

Two thick-shelled contrast agents (Quantison ${ }^{\mathrm{TM}}$, M1639), inserted through a cellulose capillary, were subjected to $3 \mathrm{MHz}$, high-MI pulsed ultrasound from a Toshiba SSA$770 \mathrm{~A} \mathrm{CV}$ ultrasound machine, and synchronously recorded by camera through a high numerical aperture microscope. Quantison $^{\text {TM }}$ (Upperton Limited, Nottingham, UK) consists of human serum albumin-encapsulated air bubbles with a mean diameter of $3.2 \mu \mathrm{m}$. Shell thicknesses are between 0.2 and $0.3 \mu \mathrm{m}$ [8]. The resonance frequency of the bulk agent is $4 \mathrm{MHz}$ [8]. M1639 (POINT Biomedical Corporation, San Carlos, CA) consists of bilayered microspheres encapsulating nitrogen bubbles with a mean diameter of $4 \mu \mathrm{m}$. The outermost layer is albumin and the inner layer is composed of a biodegradable polymer. The shell thickness is proportional to the bubble diameter. The resonance frequency of M1639 lies above $6 \mathrm{MHz}$. Both agents investigated were acoustically detectable. 

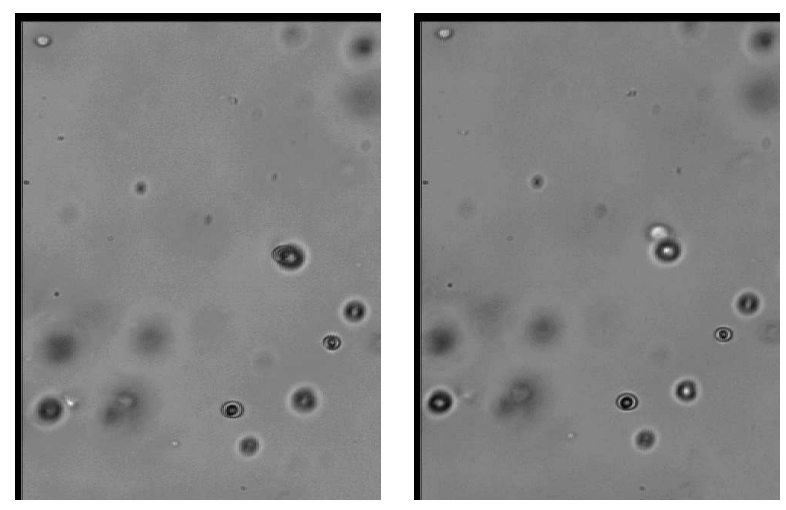

Fig. 4. Quantison ${ }^{\mathrm{TM}}$ microbubbles subjected to pulsed ultrasound from a commercial echo machine, operating at a $3 \mathrm{MHz}$ center frequency and a mechanical index MI=1.5. Inter-frame time is 100 $\mathrm{ms}$. The frame corresponds to a $94.4 \times 70.8 \mu \mathrm{m}^{2}$ area.

\section{RESULTS AND DISCUSSION}

Thick-shelled bubbles have demonstrated gas release during a high-amplitude ultrasonic cycle [9], [10]. The increased pressure difference between inside and outside of the bubble during the expansion phase [11] of the wave causes the shell to be stretched across a critical deformation, resulting into its mechanical cracking. The released bubble has an oscillation amplitude much higher than an encapsulated bubble of the same size. Figure 4 shows Quantison ${ }^{\mathrm{TM}}$ microbubbles subjected to pulsed ultrasound from a commercial echo machine, operating at a $3 \mathrm{MHz}$ center frequency and a mechanical index MI=1.5. Clearly, one bubble demonstrates disruption. The released bubble has been observed to dissolve in subsequent frames.

Figure 6 shows an image sequence of M1639 microbubbles under high-MI insonification. The direction of the ultrasound beam is right-to-left. In frame 1, the microbubbles are distributed unevenly in the right of the frame. In frame 10 , two clusters have been formed. In the subsequent frames, these clusters travel in the direction of the ultrasound.

The hexagons in frame 1 mark two microbubbles with $3 \mu \mathrm{m}$ diameters. There approach has been measured and computed with equation (1), assuming $\kappa=5 \times 10^{-7} \mathrm{~m}^{2} \mathrm{~N}^{-1}$. The result is shown in Figure 5. The fact that the measured distances are lower than those computed has been attributed to the presence of surrounding bubbles.

\section{Conclusions}

At this acoustic amplitude, the agent Quantison ${ }^{\mathrm{TM}}$ did not translate, but showed a small percentage of disrupted bubbles. The agent M1639 showed the ultrasound-induced formation of bubble clusters, and the translation thereof towards the capillary boundary. Disruption and/or gas release was observed from some bubbles, who, after release, continued translating. It is concluded, that forced translation and clustering of thick-shelled contrast microbubbles is feasible at high MI.

\section{ACKNOWLEDGMENTS}

The authors are grateful to POINT Biomedical Corporation, San Carlos, CA, for supplying the contrast agent M1639 and to Upperton Limited, Nottingham, UK, for supplying the contrast agent Quantison ${ }^{\mathrm{TM}}$.

\section{REFERENCES}

[1] J. D. Lathia, L. Leodore, and M. A. Wheatley, "Polymeric contrast agent with targeting potential," Ultrasonics, vol. 42, pp. 763-768, 2004.

[2] S. Zhao, M. Borden, S. H. Bloch, D. Kruse, K. W. Ferrara, and P. A. Dayton, "Radiation-force assisted targeting facilitates ultrasonic molecular imaging," Mol. Imaging, vol. 3, no. 3, pp. 135-148, 2004.

[3] P. A. Dayton, K. E. Morgan, A. L. Klibanov, G. Brandenburger, K. R. Nightingale, and K. W. Ferrara, "A preliminary evaluation of the effects of primary and secondary radiation forces on acoustic contrast agents," IEEE Trans. Ultrason., Ferroelect., Freq. Contr., vol. 44, no. 6, pp. 1264-1277, 1997.

[4] P. Dayton, A. Klibanov, G. Brandenburger, and K. Ferrara, "Acoustic radiation force in vivo: a mechanism to assist targeting of microbubbles," Ultrasound Med. Biol., vol. 25, no. 8, pp. 1195-1201, 1999.

[5] M. Postema, A. van Wamel, C. T. Lancée, and N. de Jong, "Ultrasound-induced encapsulated microbubble phenomena," Ultrasound Med. Biol., vol. 30, no. 6, pp. 827-840, 2004.

[6] A. J. Reddy and A. J. Szeri, "Coupled dynamics of translation and collapse of acoustically driven microbubbles," J. Acoust. Soc. Am., vol. 112, no. 4, pp. 1346-1352, 2002.

[7] F. R. Young, Cavitation. Maidenhead: McGraw-Hill, 1989.

[8] P. J. A. Frinking and N. de Jong, "Acoustic modeling of shellencapsulated gas bubbles," Ultrasound Med. Biol., vol. 24, no. 4, pp. 523-533, 1998.

[9] S. H. Bloch, M. Wan, P. A. Dayton, and K. W. Ferrara, "Optical observation of lipid- and polymer-shelled ultrasound microbubble contrast agents," Appl. Phys. Lett., vol. 84, no. 4, pp. 631-633, 2004.

[10] M. Postema, A. Bouakaz, M. Versluis, and N. de Jong, "Ultrasoundinduced gas release from contrast agent microbubbles," IEEE Trans. Ultrason., Ferroelect., Freq. Contr., vol. 52, no. 6, pp. 1035-1041, 2005.

[11] M. Postema, A. Bouakaz, F. J. ten Cate, G. Schmitz, N. de Jong, and A. van Wamel, "Nitric oxide delivery by ultrasonic cracking: some limitations," Ultrasonics, vol. 44, p. doi:10.1016/j.ultras.2006.06.003, 2006.

Michiel Postema e-mail: postema@ieee.org

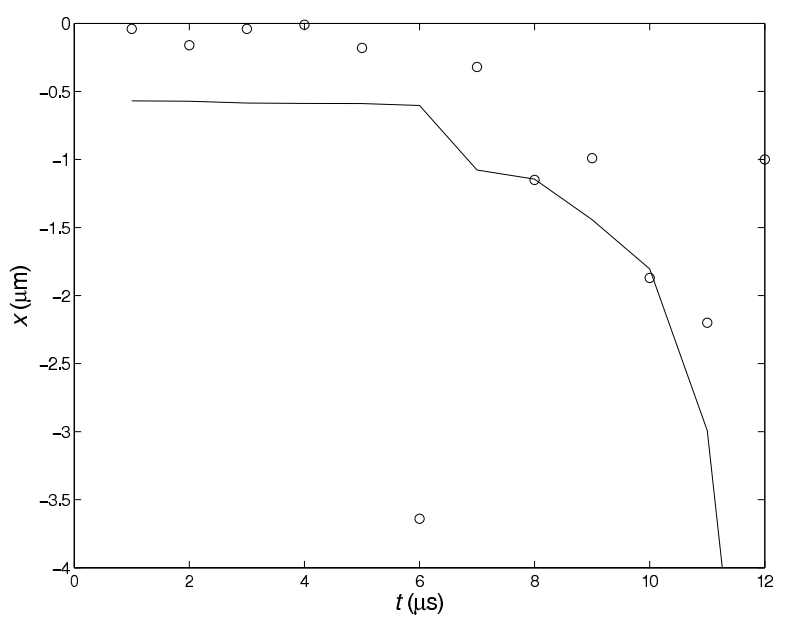

Fig. 5. Measured and computed traveled distances $x(t)$ of two identical $r_{0}=1.5 \mu \mathrm{m}$ M1639 microbubbles, assuming $\kappa=5 \times 10^{-7}$ $\mathrm{m}^{2} \mathrm{~N}^{-1}$. 


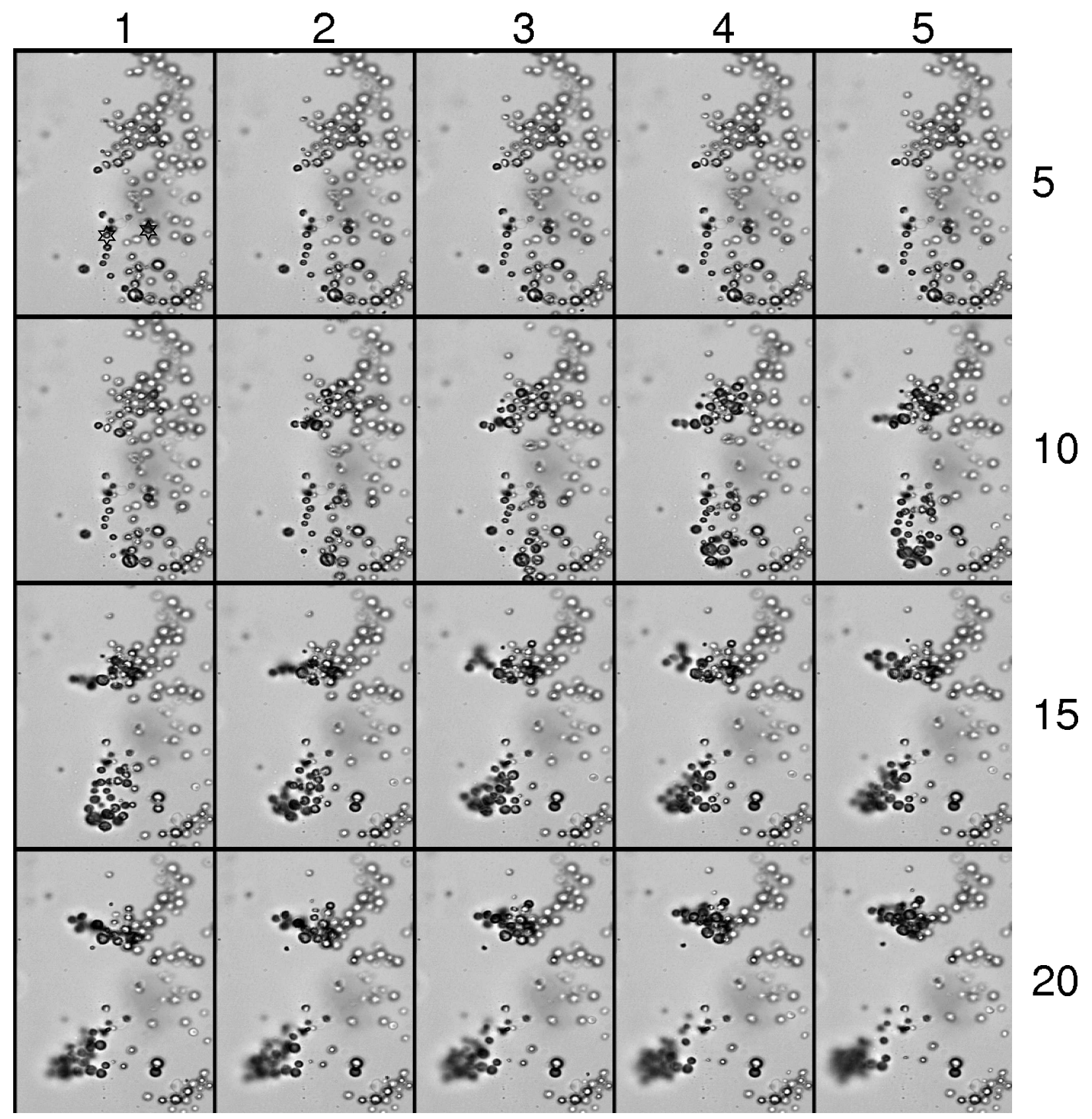

Fig. 6. M1639 microbubbles subjected to pulsed ultrasound from a commercial echo machine, operating at a $3 \mathrm{MHz}$ center frequency and a mechanical index MI=1.3. Inter-frame time is $100 \mathrm{~ms}$. The frame corresponds to a $94.4 \times 70.8 \mu \mathrm{m}^{2}$ area. 